\title{
Synthesis and Characterization of Sodium Bis(2-ethylhexyl) Sulfonsuccinate (AOT) Capped Pure and Mn-Doped CdS Nanoparticles
}

\author{
D. Venkatesan, ${ }^{1}$ D. Deepan, ${ }^{2}$ J. Ramkumar, ${ }^{3}$ S. Moorthy Babu, ${ }^{3}$ and R. Dhanasekaran ${ }^{3}$ \\ ${ }^{1}$ Department of Materials Science and Engineering, KTH 100-44 Stockholm, Sweden \\ ${ }^{2}$ Department of Metallurgy and Materials Science and Engineering, KU Leuven, 3001 Heverlee, Belgium \\ ${ }^{3}$ Crystal Growth Centre, Anna University, Chennai 600025, India
}

Correspondence should be addressed to R. Dhanasekaran, rdcgc@yahoo.com

Received 4 October 2011; Accepted 13 December 2011

Academic Editor: Edward Andrew Payzant

Copyright ( 2012 D. Venkatesan et al. This is an open access article distributed under the Creative Commons Attribution License, which permits unrestricted use, distribution, and reproduction in any medium, provided the original work is properly cited.

\begin{abstract}
CdS nanoparticles and thin films are well known for their excellent semiconducting properties. When transition metal ions are doped into the CdS, it exhibits magnetic properties in addition to semiconducting properties and they are termed as dilute magnetic semiconductors (DMSs). In this paper, we discuss the preparation of sodium bis(2-ethylhexyl) sulfonsuccinate (AOT) capped CdS nanoparticles and thin films doped with magnetic impurity Mn. Sodium bis(2-ethulexyl) sulfonsuccinate (AOT), capping agent promotes the uniform formation of nanoparticles. Optical characterizations are made using the UV-Vis spectrometer, PL, and FTIR. XRD shows the hexagonal structure of the CdS. SEM images and EDS measurements were made for the thin films. EPR shows the clear hyperfine lines corresponding to $\mathrm{Mn}^{2+}$ ion in the CdS nanoparticles.
\end{abstract}

\section{Introduction}

Nanostructured materials, especially II-VI semiconductors, have become a subject of intensive research for their extraordinary properties compared to bulk material [13]. Semiconductor nanocrystalline materials which have diameters less than their bulk exciton diameter display sizedependent optical properties due to the quantum confinement. As a result of size quantization, the absorption spectrum gets blue-shifted which indicates the decrease in crystallite size [4]. Manganese-doped CdS nanocrystals have been mainly studied due to their luminescence properties. Synthesis of these doped nanocrystals has become a major interdisciplinary field of research during the past decades. This is due to the fact that the $\mathrm{Mn}^{2+}$ ions provide good traps for the excited electrons, which give rise to their potential use in the fields of nonlinear optics, luminescence, electronics, and optoelectronic devices [5-10]. The localized $d$ orbital electrons of the magnetic dopant ions couple with the electrons in the semiconducting band of the host material. This coupling phenomena lead to number of interesting and peculiar properties such as magnetoelectrical and magneto optical effects.

In the present work, we explained the simple attempts made to prepare the sodium bis(2-ethulexyl) sulfonsuccinate (AOT) capped cadmium sulphide nanoparticles and found varying absorption spectra with AOT capping and their stability with variation of capping concentration are reported. The option of AOT was considered since they have better possibilities of improved size control on the formation of CdS nanoparticles. AOT is a double-chain anionic surfactant and a well-known capping agent for semiconductor nanoparticles. Use of AOT creates interesting optical properties of AOT capped CdS nanoparticles which is another motivating factor. Figure 1 shows the structure of anionic surfactant AOT [11].

In the capping process, the organic solvents are absorbed on the surface of the CdS nanoparticles, and this produces the negative charge on the surface of the particles due to polarization. This leads to the repulsive force among the capped nanoparticles. This repulsive force is capable of keeping very small nanoparticles $(d<10 \mathrm{~nm})$ to suspend 


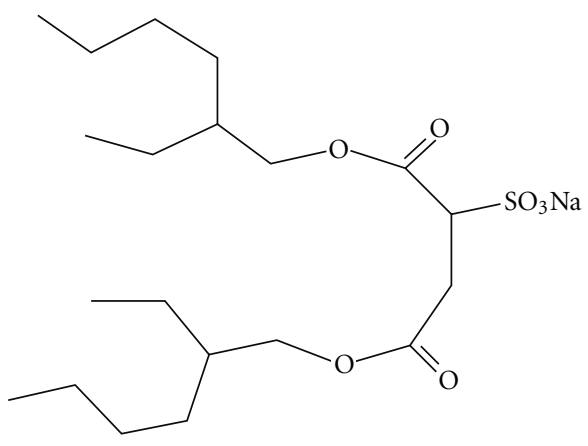

FIgURE 1: Structure of AOT.

on the solution, where the larger particles settle down at the bottom. Varying the concentration of the capping agent, the particle size can be changed, and, in this work, we have optimized the concentration of capping agent and proceeded with the magnetic dopants in CdS and their magnetic properties are studied.

\section{Preparation}

CdS nanoparticles were prepared by simple chemical process. Following [12], we have adopted a simple method for the synthesis. The general procedure includes $0.01 \mathrm{M}$ of $\mathrm{CdCl}_{3}$, and of $0.01 \mathrm{M}$ of $\mathrm{Na}_{2} \mathrm{~S}$ were dissolved in separate containers containing $20 \mathrm{~mL}$ distilled water. $0.1 \mathrm{M}$ dioctyl sodium sulfonsuccinate (AOT) solution in $10 \mathrm{~mL}$ hexane was created beforehand. $5 \mathrm{~mL}$ of the $\mathrm{CdCl}_{2}$ solution and $5 \mathrm{~mL}$ of the $\mathrm{Na}_{2} \mathrm{~S}$ solution were taken into separate beakers. 0.1 M AOT in hexane solutions were mixed into the two solutions and were allowed to stir for 30 minutes using a magnetic stirrer. In order to get the best emulsion, these aqueous solutions were injected into AOT in hexane as rapidly as possible. These respective $\mathrm{CdCl}_{2} / \mathrm{AOT} /$ hexane and $\mathrm{Na}_{2} \mathrm{~S} / \mathrm{AOT} /$ hexane solutions were allowed to stir for $30 \mathrm{~min}$ before being mixed together and allowed to stir for an additional $30 \mathrm{~min}$. Both the solutions were mixed together and allowed to stir for another 30 minutes using magnetic stirrer. AOT, capping agent is introduced to constrain the particle size. The particle size depends mainly on the concentration of the capping agent [13]. The initial preparation was done with a concentration of $0.1 \mathrm{M}$. The similar procedure was adopted, and the concentration of AOT was varied from $0.04 \mathrm{M}$ to $1 \mathrm{M}$.

The samples were characterized by powder X-ray diffraction employing $\mathrm{Cu} \mathrm{K}_{\alpha}$ radiation. The electron paramagnetic resonance spectra were taken using Bruker EMX EPR Spectrometer.

\section{Results and Discussions}

It is found that the absorbance peak is red-shifted when AOT concentration was increased from 0.04 to $1 \mathrm{M}$. This indicates the increase in particle size with increase in the concentration of capping agent. The band gap of the CdS nanoparticles is a function of the particle size under tight binding approximation (TBA) as well as effective mass approximations (EMA). The experimental data agree well with the effective mass calculations for diameters larger than $4 \mathrm{~nm}$ where as TBA fit better for particles with diameters smaller than $4 \mathrm{~nm}$ [14]. Murakoshi et al. [15] have reported that the experimental data for the dependence of band gap with particle size agrees well with EMA with a finite potential well, even for smaller sizes. The relationship between the particle size $d$ and band gap $E g$ is given by

$$
E_{g}=E_{g}(0)+\frac{\alpha}{d^{\beta}},
$$

where $\operatorname{Eg}(0)$ is the band gap for bulk CdS $(2.42 \mathrm{eV}), \alpha$ and $\beta$ are constants. The value of $\beta=2$ for EMA [16]. The data taken from Lippens and Lannoo [17] for the relationship between band gap and particle size under EMA were solved using the above relation, and the values of $\alpha$ and $\beta$ were obtained as $13 \mathrm{eV} / \mathrm{nm}^{2}$ and 2 , respectively. Thus, greater blue shift was observed at $0.04 \mathrm{M}$ AOT capped CdS nanoparticles, which infers the smaller size compared to higher concentration of AOT. This was confirmed from the UV-VIS measurements taken immediately after preparation.

The optical absorption as a function of wavelength for CdS particles with various capping concentrations is shown in Figure 2(a). It can be seen from the figure that the absorption edge shifts towards shorter wavelength region as the concentration of AOT is decreased, indicating the formation of CdS particles in the nanometer regime [18]. It can also be seen that, as the AOT concentration is decreased, excitonic peaks appear which is an indication of increase in band gap and decrease in particle size. Haruff and Bunker [19] have reported the appearance of an excitonic peak at around $310-380 \mathrm{~nm}$ for AOT capped CdS nanoparticles prepared in different ratio of $\mathrm{H}_{2} \mathrm{O} / \mathrm{AOT}$. Pileni [20] has also reported the presence of the excitonic peak at the range of $380 \mathrm{~nm}$ to $420 \mathrm{~nm}$ for AOT protected CdS nanoparticles. From Figure 2(a), for the stabilizer concentration of $0.04 \mathrm{M}$ AOT, excitonic peaks were observed at around $422 \mathrm{~nm}$ in the present study, indicating the formation of CdS particles of smaller particle size but may be larger than earlier reported [20]. The excitonic peaks appear at $432 \mathrm{~nm}$ and $447 \mathrm{~nm}$ for the $0.07 \mathrm{M}$ and $0.1 \mathrm{M}$ AOT indicating the gradually increase in the particle size.

Figure 2(b) shows the optical absorption spectra for $\mathrm{Mn}$-doped CdS nanoparticles. The excitonic peak appears at approximately $459 \mathrm{~nm}$, which is red-shifted. This red shift indicates the decrease in band gap and also represents increase in the particle size.

Thus, we can conclude that, when the concentration of AOT is smaller, greater blue shift is observed, which refers to smaller particle size. The optimum concentration of the AOT to prepare $\mathrm{Mn}$-doped CdS nanoparticles is $0.04 \mathrm{M}$.

The photoluminescence spectra of CdS have been extensively studied. The role of surface and native defects has been used to explain the behavior of the PL. In PL, a strong and narrow emission peak at $488 \mathrm{~nm}$ was observed when the sample was excited at $280 \mathrm{~nm}$ light as shown in Figure 3(a). The luminescence at $488 \mathrm{~nm}$ may be due to a higher level transition in CdS crystallites. It has been reported that this kind of band-edge luminescence 


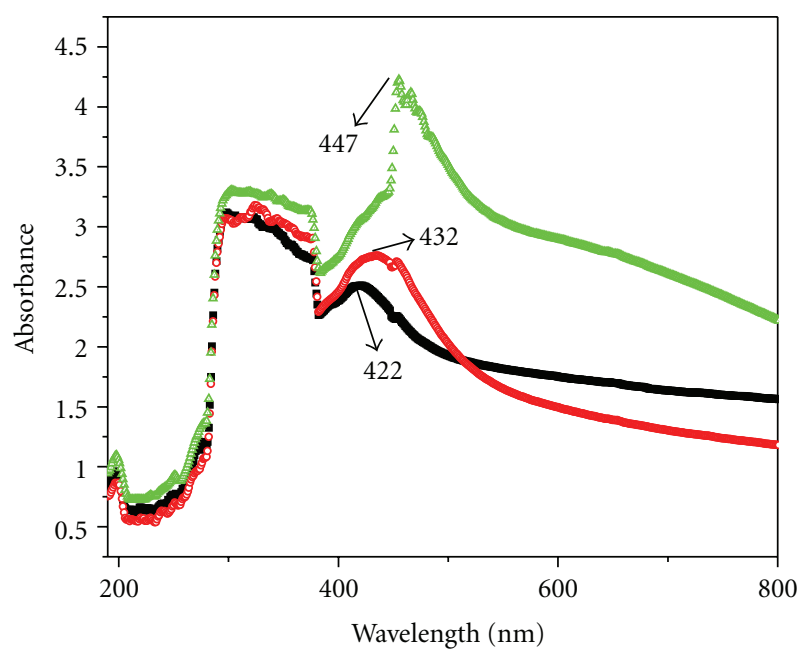

- $0.04 \mathrm{M} \mathrm{AOT}$

○ $0.07 \mathrm{M} \mathrm{AOT}$

$\triangle 0.01 \mathrm{M} \mathrm{AOT}$

(a)

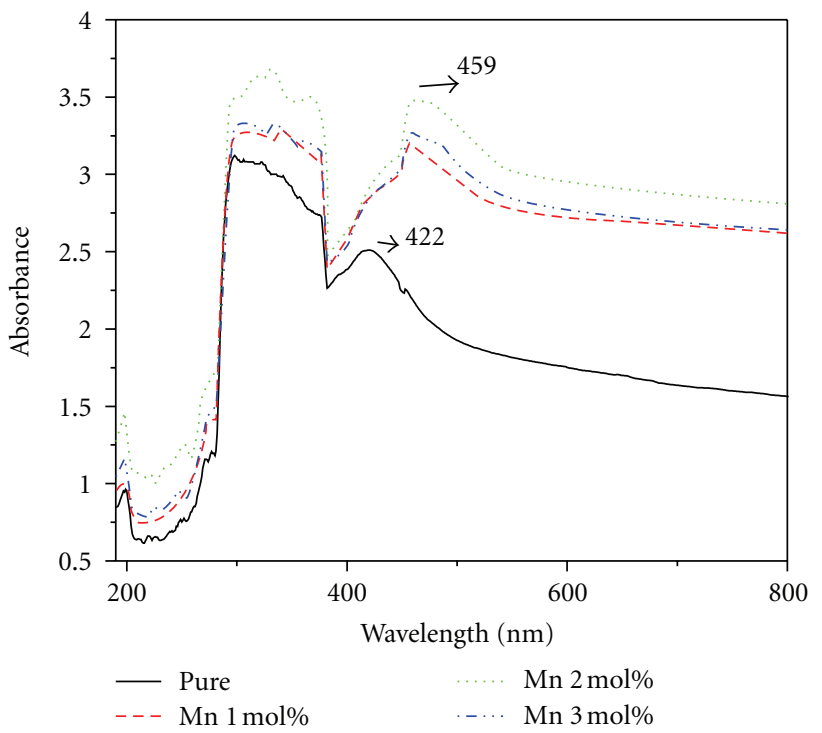

(b)

Figure 2: (a) Absorption spectra of CdS nanoparticles prepared at different concentrations of AOT. (b) Absorption spectra of pure and doped CdS nanoparticles.

arises from the recombination of excitons and/or shallowly fascinated electron-hole pairs. A slight hump is present at $530 \mathrm{~nm}$, which can be ascribed to the surface defect emission of the CdS nanoparticles. In contrast to the above, the PL spectrum of Mn-doped CdS sample shows an additional red-shifted emission featured at $575 \mathrm{~nm}$, due to an internal ${ }^{4} \mathrm{~T}_{1} \rightarrow{ }^{6} \mathrm{~A}_{1} \mathrm{Mn}^{2+}$ transition [21], indicating huge spectra overlapping between the emission from $\mathrm{Mn}^{2+}$ ions and the emission from surface states. So a capable energy transfer from the excited carriers intent at the surfaces to $\mathrm{Mn}$ ions occurs in our CdS:Mn sample [22, 23]. Generally, it is known that the photoluminescence in semiconductors is greatly influenced by the stoichiometric defects at electronic

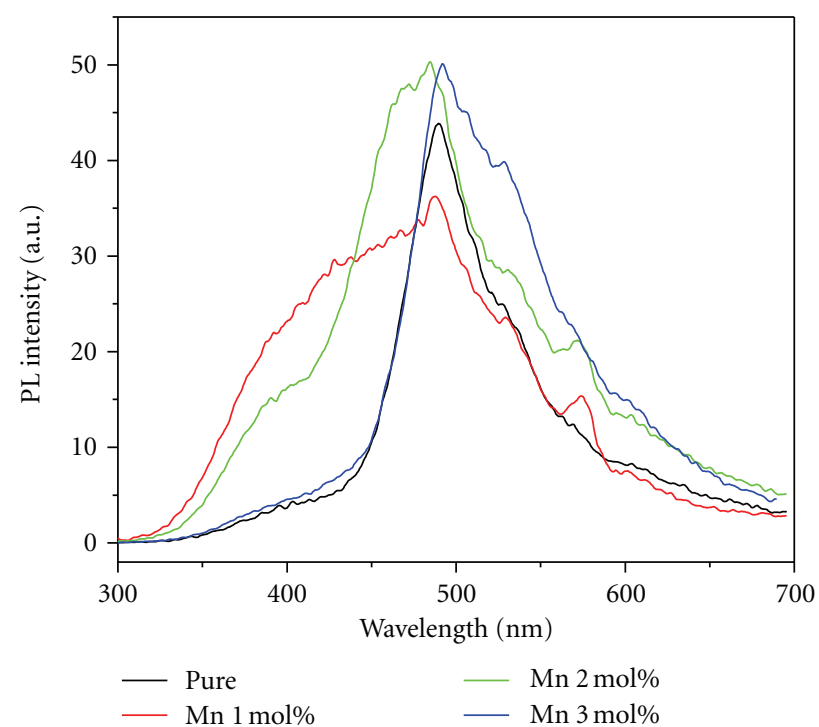

(a)

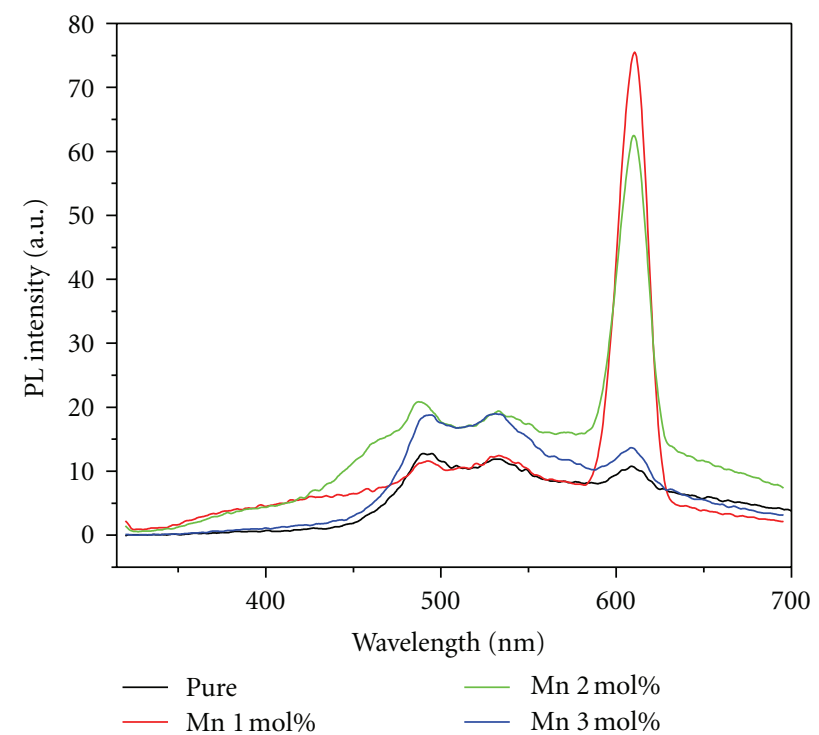

(b)

Figure 3: (a) Photoluminescence of the system excited at $280 \mathrm{~nm}$ $\left(\lambda_{\mathrm{ex}}=280 \mathrm{~nm}\right)$, (b) system excited at $300 \mathrm{~nm}\left(\lambda_{\mathrm{ex}}=300 \mathrm{~nm}\right)$.

levels. The variation in the intensity of the characteristic peaks shows considerable changes in the stability and size of the nanoparticles. Thus, slight difference is found in the absorption edge as well as the photoluminescence peak positions observed for the pure and the doped samples, which indicates a slight variation in size and stability [24].

Figure 3(b) shows a distinct peak at $488 \mathrm{~nm}$, when excited at $300 \mathrm{~nm}$ light. This is the characteristic peak. An additional red-shifted peak at $545 \mathrm{~nm}$ is also present which represents the defect emission peak. The intensity of the surface defect emission increases as the Mn dopant percentage increases. The Mn (2\%) doped sample shows a broad peak compared to the others; this can be attributed to large surface defects present. The peak at $600 \mathrm{~nm}$ is due to the excitation itself. 
FTIR spectra of AOT, pure and AOT capped CdS nanoparticles are shown in the Figure 4. The $\mathrm{CH}$ stretching band is characterized by four peaks $(2861,2874,2932$, and $2960 \mathrm{~cm}^{-1}$ ) due to the symmetric and antisymmetric stretching vibrations of $\mathrm{CH}_{2}$ and $\mathrm{CH}_{3}$ groups of the AOT alkyl chains [25]. The absorption peak around $1047 \mathrm{~cm}^{-1}$ is due to the $\mathrm{CH}_{2}$ twist [26]. With the overall observations, it can be concluded that the AOT has formed a coating over the cadmium sulfide nanoparticles, which in turn supports their influence on size reduction. There was no formation of sulphate compounds. The obtained results are tabulated in Table 1.

The pure and doped CdS nanoparticle solutions are deposited on glass substrate heated at $80^{\circ} \mathrm{C}$. The XRD pattern of the deposited film is shown in Figure 5. From the JCPDS (file no. 10-0454) cards, the peaks of the pure CdS are marked. The planes corresponding to CdS are marked. The peaks at angle $2 \theta=25.96^{\circ}, 29.98^{\circ}, 35.44^{\circ}$, and $43.58^{\circ}$ correspond to the planes [002] [101], [102], and [110], respectively, which confirms that the CdS thin films are having the hexagonal crystalline structure. CdS exhibits both hexagonal and cubic crystalline structures. The planes [002] and [101] represent the hexagonal structure of CdS. The intensity of the peaks was found to be very weak which refers the poor crystallinity of the materials that is being deposited. Since the CdS nanoparticles are being capped with AOT, the X-ray beam falls on the amorphous AOT and reduces the intensity of the peaks of the CdS nanostructured thin films. Since the AOT is a polymer compound and being amorphous, they do not show sharp peaks as like the crystalline materials. And no peaks of the secondary phase $\mathrm{NaCl}$ were found, and it is very clear from the EDX data which confirms the absence of the chlorine in the entire system.

Moreover, the as-deposited samples usually lack in the crystallinity, and similar results were reported $[27,28]$. When thin films are annealed, the crystallinity of the thin films may increase.

Figure 6(a) shows SEM images of pure CdS nanoparticles deposited on a glass plate. We can observe more surface irregularities like ridges from the SEM images but are not visible cracks. The CdS nanoparticles, embedded in the AOT matrix, indicate that the sample is mixed with large number of well dispersed with irregular shape and size. Figure 6(b) shows the cluster of nanoparticles at higher resolution. But most of the particles appear to be spherical in shape.

Figure 7(a) shows SEM images of Mn (1 mol \%) doped CdS thin films. It is observed that the films are not uniform throughout the regions, but the films are without any void, pinhole, or cracks and they cover the substrates well. Figure 7(b) shows the structure of nanoparticles at higher magnification. We can infer that the clusters like patterns are formed due to the agglomeration of constituent particles. The images show presence of larger cluster.

Figure 8 (a) shows images of $\mathrm{Mn}(2 \mathrm{~mol} \%)$ doped CdS thin films. There we clearly observe the small-nanosized grains engaged in a fibrous-like structure, which clearly indicates the nanocrystalline nature along with some agglomerated phase of CdS thin films. The fibrous-like structure is

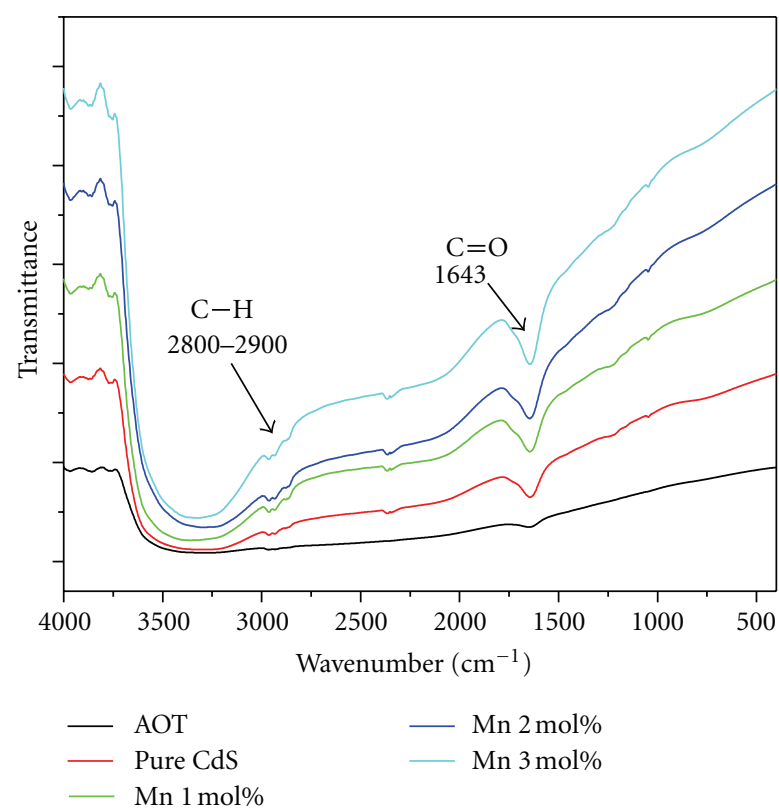

Figure 4: FT-IR spectra of the CdS system.

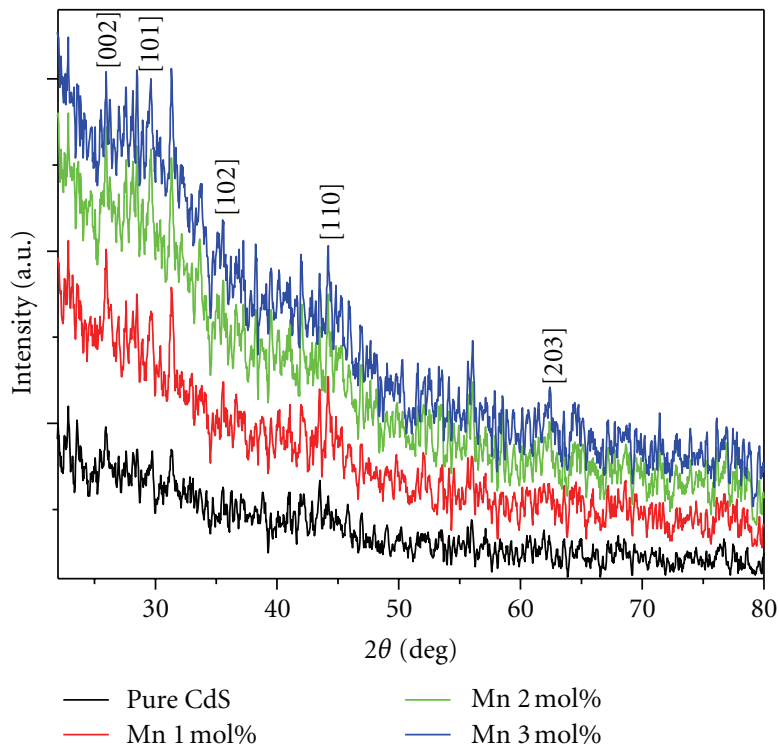

FIGURE 5: XRD patterns of the pure and Mn: CdS thin films.

TABLE 1: FT-IR spectra of CdS system.

\begin{tabular}{lcc}
\hline S. no. & $\begin{array}{c}\text { Wave number } \\
\mathrm{cm}^{-1}\end{array}$ & Bonding \\
\hline$(1)$ & 2960 & $v_{\mathrm{as}}\left(\mathrm{CH}_{3}\right)$ \\
$(2)$ & 2932 & $v_{\mathrm{as}}\left(\mathrm{CH}_{2}\right)$ \\
$(3)$ & 2874 & $v_{\mathrm{s}}\left(\mathrm{CH}_{3}\right)$ \\
$(4)$ & 2861 & $v_{\mathrm{s}}\left(\mathrm{CH}_{2}\right)$ \\
$(5)$ & 1643 & $v(\mathrm{CO})$ of AOT \\
\hline
\end{tabular}

due to the presence of the capping agent which continued to remain even after the heating process. From these images, 


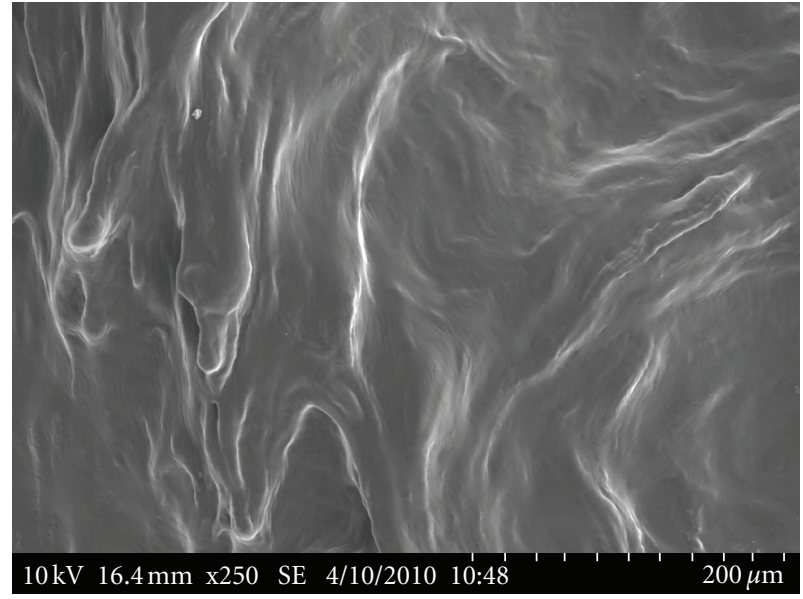

(a)

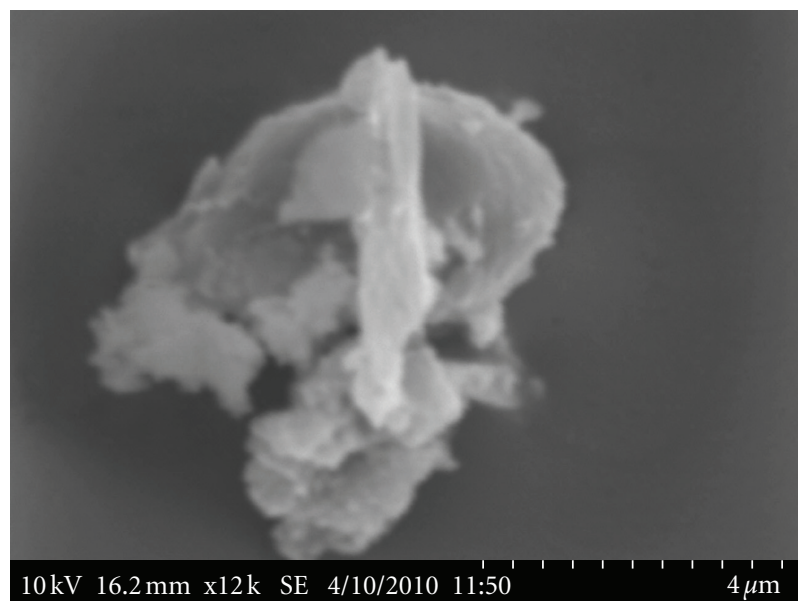

(b)

Figure 6: SEM images of pure CdS thin films: (a) lower magnification, (b) higher magnification.

grain sizes of the films are not uniform. Therefore, we estimated the grain sizes from 70 to $500 \mathrm{~nm}$. Figure 8(b) shows images of $\mathrm{Mn}(3 \mathrm{~mol} \%)$ doped CdS thin films.

The EDX report shows the purity of the sample. There is no impurity available in the sample as there is no element except the Cd, S, Mn, C, and Na in the EDX spectrum. The orbital states of Cd, S, Mn, C, and $\mathrm{Na}$ are seen in the EDX spectrum. It should be noted here that the contribution of the $S$ atoms in EDX spectrum comes from both $S$ atoms present in the AOT molecules and from those in the CdS nanoparticles. Figure 9 shows the EDX measurement for the thin films.

The amount of dopants present in the Mn:CdS thin films reveals that the $\mathrm{Mn}$ concentration increases with increase in the dopants increase. From the figure, the energy levels at $0.650 \mathrm{KeV}, 0.762 \mathrm{KeV}, 5.898 \mathrm{KeV}, 6.489 \mathrm{KeV}$, and $6.536 \mathrm{KeV}$ correspond to the $\mathrm{L}_{\mathrm{I} \alpha \beta}, \mathrm{L}_{\mathrm{II} \alpha} \beta, \mathrm{K}_{\alpha}, \mathrm{K}_{\beta}$, and $\mathrm{K}_{\alpha \beta}$ (Table 2).

Figure 10 shows the EPR spectra of the Mn-doped CdS nanoparticles solution in hexane. We can find the

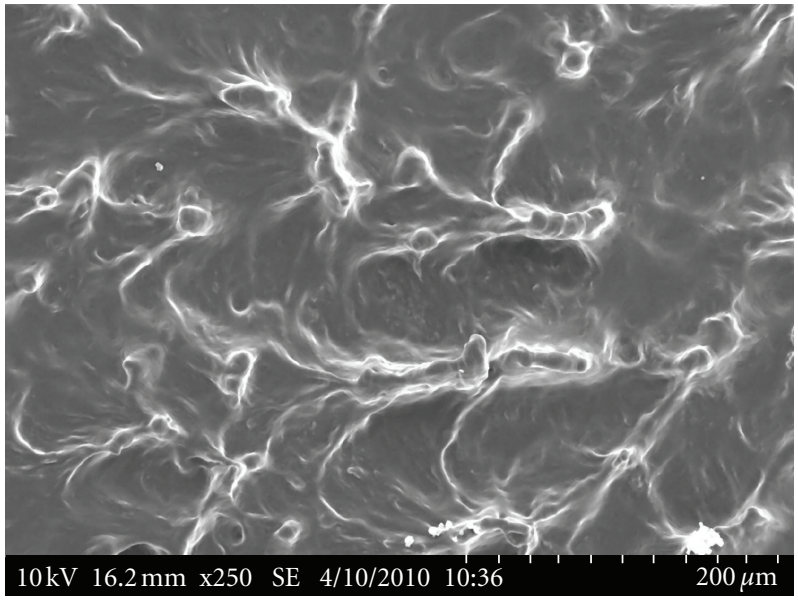

(a)

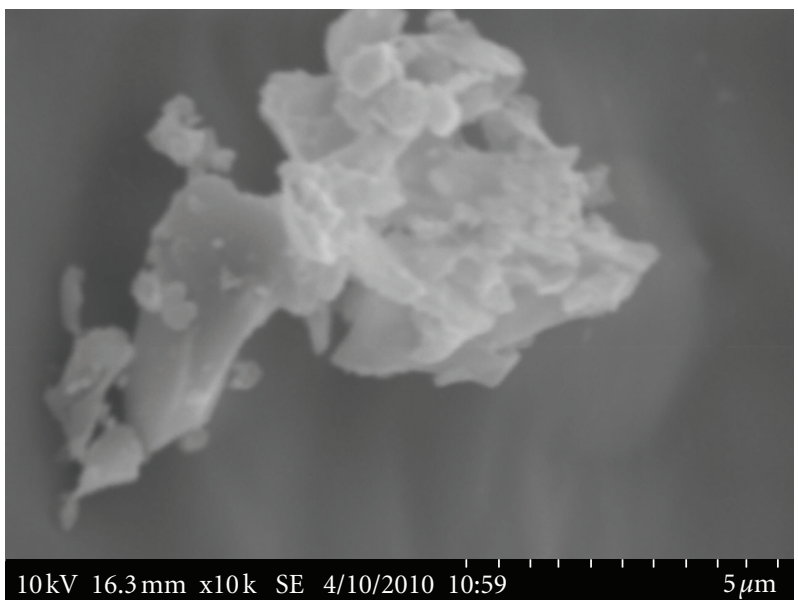

(b)

FIgure 7: SEM images of Mn (1 mol \%) doped CdS thin films: (a) lower magnification, (b) higher magnification.

TABle 2: Concentration of Mn in doped thin films.

\begin{tabular}{lcc}
\hline S. no. & System & At \% of the dopant \\
\hline$(1)$ & $1 \mathrm{~mol} \% \mathrm{Mn}$ & 0.16 \\
$(2)$ & $2 \mathrm{~mol} \% \mathrm{Mn}$ & 0.30 \\
$(3)$ & $3 \mathrm{~mol} \% \mathrm{Mn}$ & 0.55 \\
\hline
\end{tabular}

fully resolved hyperfine structure for typical $\mathrm{Mn}^{2+}\left(\mathrm{d}^{5}\right.$ configuration) at hexagonal lattice sites in CdS, and the electronic ground state is ${ }^{6} S_{5 / 2}$. As the spin of the $\mathrm{Mn}^{2+}$ is $S=5 / 2$, and the hyperfine splitting term is $(2 S+1)$. Hence EPR signal for $\mathrm{Mn}^{2+}$ in material will have six resonant lines. This configuration is due to the localized trapping of $\mathrm{Mn}^{2+}$ electron which is a substitutional dopant [29]. The intensity of the peaks in $2 \mathrm{~mol} \% \mathrm{Mn}$-doped $\mathrm{ZnO}$ is less. The reason may be due to the nonuniform distribution of $\mathrm{Mn}^{2+}$ [30] ions. The six hyperfine splitting refers to $5 / 2 \leftrightarrow 3 / 2,3 / 2 \leftrightarrow$ $1 / 2,1 / 2 \leftrightarrow-1 / 2,-1 / 2 \leftrightarrow-3 / 2$, and $-3 / 2 \leftrightarrow 5 / 2[31]$. 


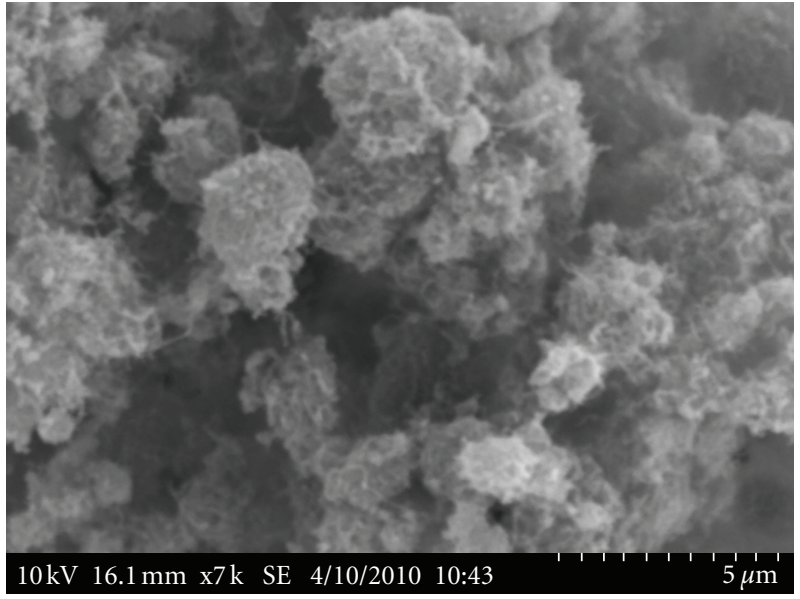

(a)

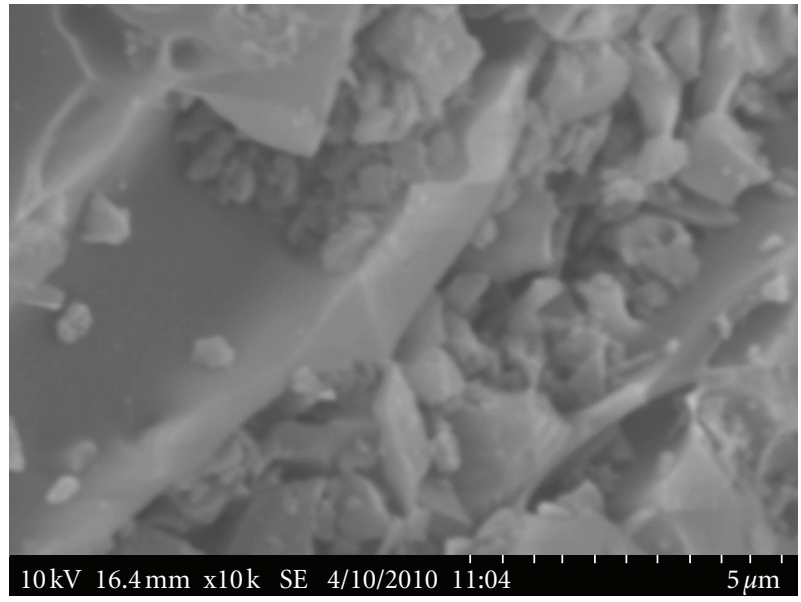

(b)

Figure 8: SEM images of (a) Mn 2 mol \%, (b) Mn 3 mol \% doped CdS thin films.

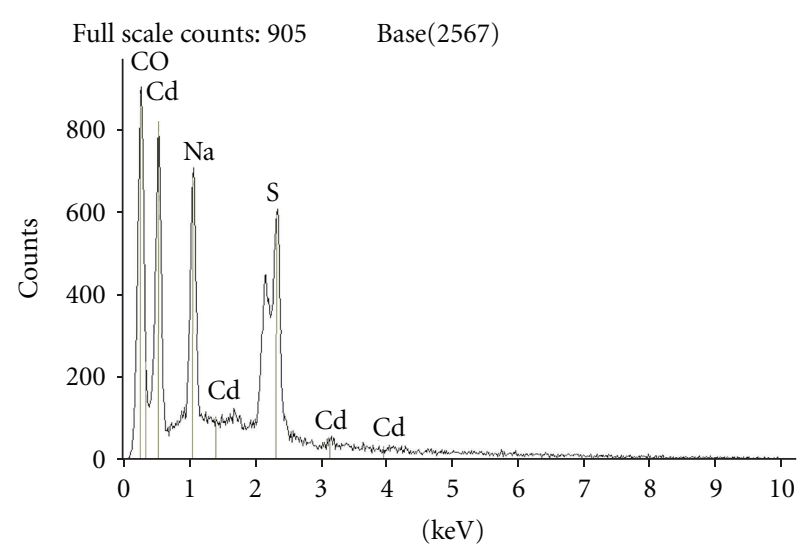

(a)

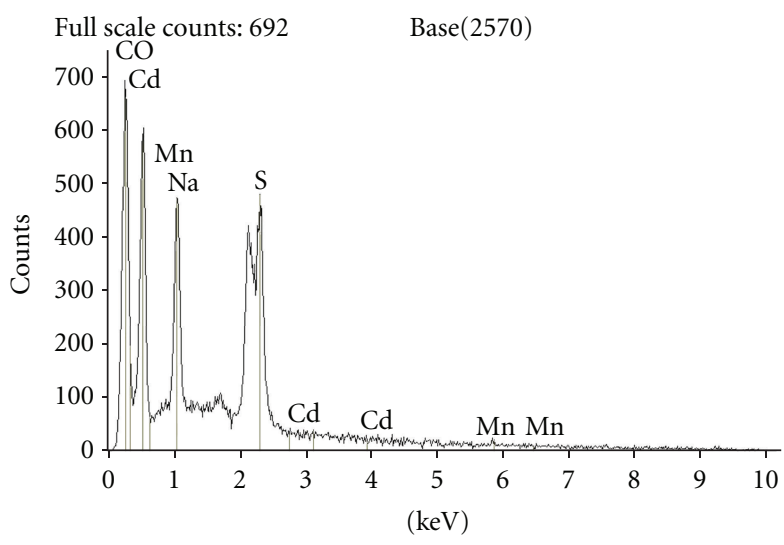

(c)

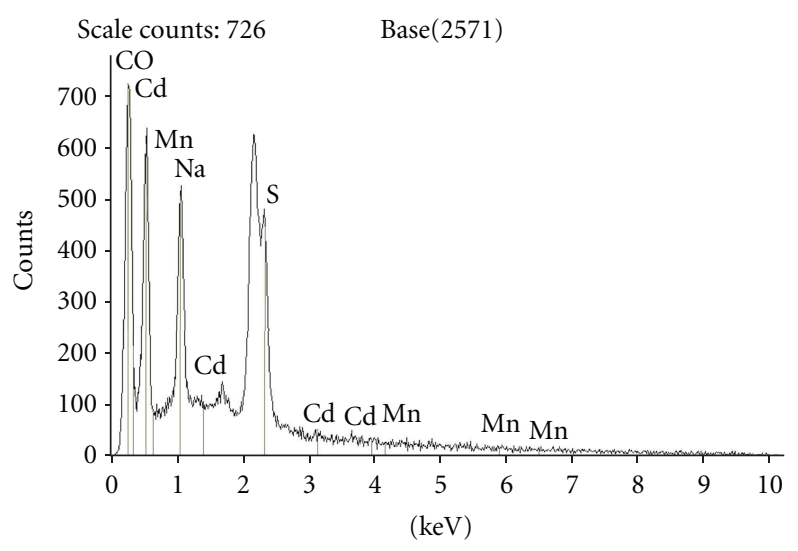

(b)

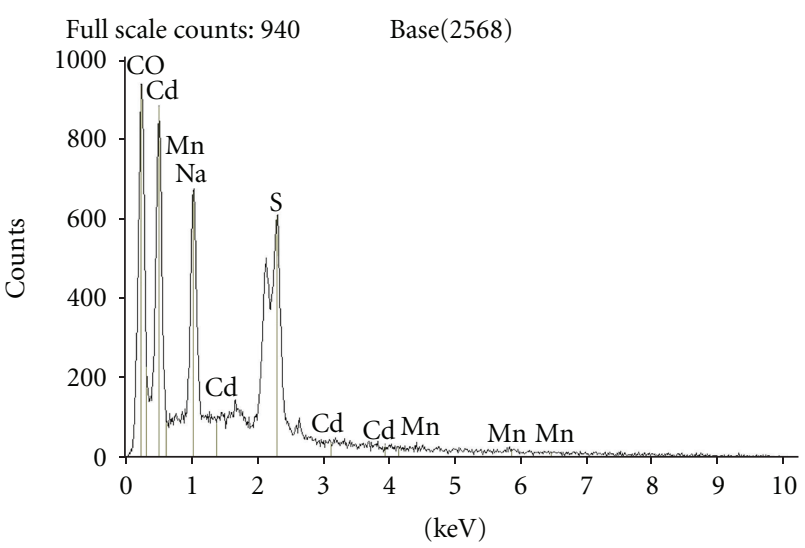

(d)

FIGURE 9: EDX spectra of (a) pure, (b) $1 \mathrm{~mol} \%$, (c) $2 \mathrm{~mol} \%$, (d) $3 \mathrm{~mol} \% \mathrm{Mn}$-doped CdS thin films.

\section{Conclusion}

The following conclusions can be drawn from the results of the study on the effect of stabilizer concentration on the formation and stability of AOT-capped CdS nanoparticles and thin films. The amount of capping agent was varied for preparing the nanomaterials. It was found the smaller the concentration of AOT, greater the blue shift which infers that the particles size reduces. Absorption peak for pure and doped CdS nanoparticles is found in visible region. 


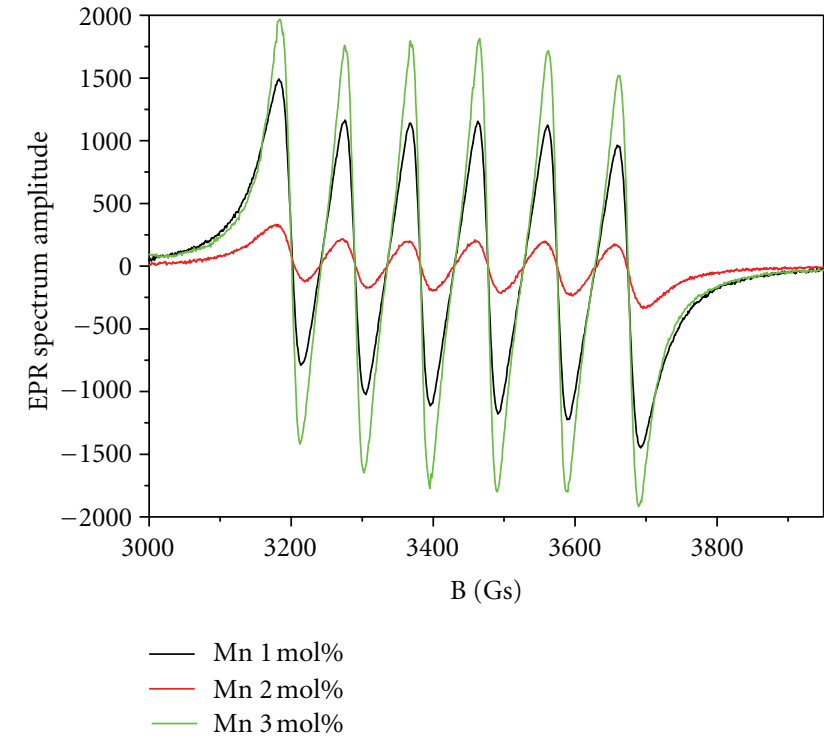

FIGURE 10: EPR spectra of Mn-doped CdS nanoparticles in hexane.

And red shift is found on the addition of dopants, and excitonic feature is greatly suppressed. In PL, emission is found near $488 \mathrm{~nm}$ at both the excitation wavelength $\left(\lambda_{\mathrm{ex}}=\right.$ $280 \mathrm{~nm}$ and $300 \mathrm{~nm}$ ) corresponds to the surface defects in the CdS system. The emission peak at $575 \mathrm{~nm}$ refers to transition of $\mathrm{Mn}^{2+}$ ion from excited state to ground state. FTIR reveals the stretching of the functional group present in the system. CdS absorption peak is found near $2361 \mathrm{~cm}^{-1}$. The nanoparticles are then deposited on glass substrate at $80^{\circ} \mathrm{C}$. XRD pattern reveals the lower crystallinity of the thin films, and small shifts are observed on addition of dopants. SEM images report the surface features, and the uniform distribution of the particles and EDX shows the concentration of $\mathrm{Mn}$ in the case of $\mathrm{Mn}$ : CdS thin films. Six hyperfine splitting are found in EPR spectra. Since the splitting is clear, this preparation method can be used in preparing Mn-doped CdS thin films using any other sophisticated instrument.

\section{Acknowledgments}

The authors are thankful to Department of Mechanical Engineering, Anna University Chennai, and Nuclear Physics, University of Madras, for extending the facilities, for characterizing the samples, and for their discussions.

\section{References}

[1] B. Tripathi, F. Singh, D. K. Avasthi, D. Das, and Y. K. Vijay, "Study of effects of $\mathrm{Mn}^{2+}$ in CdS nanocrystals," Physica B, vol. 400, no. 1-2, pp. 70-76, 2007.

[2] C. Wang, H. M. Wang, and Z. Y. Fang, "Influence of Mn doping on the microstructure and optical properties of CdS," Journal of Alloys and Compounds, vol. 486, no. 1-2, pp. 702$705,2009$.

[3] P. Sudhagar, R. Sathyamoorthy, S. Chandramohan, S. Senthilarasu, and S. H. Lee, "Synthesis of $\mathrm{Cd}_{1-x} \mathrm{Mn}_{x} \mathrm{~S}$ nanoclusters by surfactant-assisted method: structural, optical and magnetic properties," Materials Letters, vol. 62, no. 16, pp. 2430-2433, 2009.

[4] M. Pattabi and B. S. Amma, "Synthesis and stability studies of thiophenol capped CdS nanoparticles," Solar Energy Materials and Solar Cells, vol. 90, no. 15, pp. 2377-2383, 2006.

[5] B. O. Regan and M. Gratzel, "A low-cost, high-efficiency solar cell based on dye-sensitized colloidal $\mathrm{TiO}_{2}$ films," Nature, vol. 353, no. 6346, pp. 737-740, 1991.

[6] G. M. Pajonk, "Aerogel catalysts," Applied Catalysis, vol. 72, no. 2, pp. 217-266, 1991.

[7] S. Lazarouk, P. Jaguiro, S. Katsouba et al., "Stable electroluminescence from reverse biased $n$-type porous silicon-aluminum Schottky junction device," Applied Physics Letters, vol. 68, no. 12, pp. 1646-1648, 1996.

[8] R. N. Bhargava, D. Gallagher, X. Hong, and A. Nurmikko, "Optical properties of manganese-doped nanocrystals of ZnS," Physical Review Letters, vol. 72, no. 3, pp. 416-419, 1994.

[9] E. H. Nicollian and R. Tsu, "Electrical properties of a silicon quantum dot diode," Journal of Applied Physics, vol. 74, no. 6, pp. 4020-4025, 1993.

[10] S. Schmitt-Rink, D. A. B. Miller, and D. S. Chemla, "Theory of the linear and nonlinear optical properties of semiconductor microcrystallites," Physical Review B, vol. 35, no. 15, pp. 81138125, 1987.

[11] R. Premachandran, S. Banerjee, V. T. John, G. L. McPherson, J. A. Akkara, and D. L. Kaplan, "The enzymatic synthesis of thiol-containing polymers to prepare polymer-CdS Nanocomposites," Chemistry of Materials, vol. 9, no. 6, pp. 1342-1347, 1997.

[12] S. S. Shankar, S. Chatterjee, and M. Sastry, "Synthesis of CdS nanoparticles within thermally evaporated aerosol OT thin films," PhysChemComm, vol. 6, pp. 36-39, 2003.

[13] U. Winkler, D. Eich, Z. H. Chen, R. Fink, S. K. Kulkarni, and E. Umbach, "Detailed investigation of CdS nanoparticle surfaces by high-resolution photoelectron spectroscopy," Chemical Physics Letters, vol. 306, no. 1-2, pp. 95-102, 1999.

[14] A. C. Rastogi, Physics of Semiconductor Devices, V. Kumar, S. K. Agarwal, Eds., Narosa Publishing House, 1998.

[15] K. Murakoshi, H. Hosokawa, M. Saitoh et al., "Preparation of size-controlled hexagonal CdS nanocrystallites and the characteristics of their surface structures," Journal of the Chemical Society, Faraday Transactions, vol. 94, no. 4, pp. 579586, 1998.

[16] V. A. Singh and V. Ranjan, Physics of Semi conductor Devices, V. Kumar, S. K. Agarwal, Eds., Narosa Publishing House, 1996.

[17] P. E. Lippens and M. Lannoo, "Calculation of the band gap for small CdS and ZnS crystallites," Physical Review B, vol. 39, no. 15, pp. 10935-10942, 1989.

[18] M. Pattabi and B. S. Amma, "Synthesis and stability studies of thiophenol capped CdS nanoparticles," Solar Energy Materials and Solar Cells, vol. 90, no. 15, pp. 2377-2383, 2006.

[19] B. A. Haruff and C. E. Bunker, "Spectral properties of AOTprotected CdS nanoparticles: quantum yield enhanced by photolysis," Langumir, vol. 19, pp. 893-897, 2009.

[20] M. P. Pileni, "II-VI semiconductors made by soft chemistry Syntheses and optical properties," Catalysis Today, vol. 58, no. 2, pp. 151-166, 2000.

[21] S. M. Liu, F. Q. Liu, H. Q. Guo, Z. H. Zhang, and Z. G. Wang, "Surface states induced photoluminescence from $\mathrm{Mn}^{2+}$ doped CdS nanoparticles," Solid State Communications, vol. 115, no. 11, pp. 615-618, 2000.

[22] C. Cheng, G. Xu, H. Zhang, H. Wang, J. Cao, and H. Ji, "Solvothermal synthesis and photoluminescence properties 
of single-crystal $\mathrm{Mn}^{2+}$ doped CdS nanowires," Materials Chemistry and Physics, vol. 97, no. 2-3, pp. 448-451, 2006.

[23] M. A. Malik, P. O’Brien, and N. Revaprasadu, "Synthesis of TOPO-capped MN-doped $\mathrm{ZnS}$ and CdS quantum dots," Journal of Materials Chemistry, vol. 11, no. 9, pp. 2382-2386, 2001.

[24] D. Kaushik, R. R. Singh, M. Sharma, D. K. Gupta, N. P. Lalla, and R. K. Pandey, "A study of size dependent structure, morphology and luminescence behavior of CdS films on Si substrate," Thin Solid Films, vol. 515, no. 18, pp. 7070-7079, 2007.

[25] G. Calvaruso, A. Ruggirello, and V. Turco Liveri, "FT-IR investigation of the N-methylurea state in AOT reversed micelles," Journal of Nanoparticle Research, vol. 4, no. 3, pp. 239-246, 2002.

[26] Z. Lai and P. Wu, "Investigation on the conformations of AOT in water-in-oil microemulsions using 2D-ATR-FTIR correlation spectroscopy," Journal of Molecular Structure, vol. 883-884, no. 1-3, pp. 236-241, 2008.

[27] M. Ichimura, F. Goto, Y. Ono, and E. Arai, "Deposition of $\mathrm{CdS}$ and $\mathrm{ZnS}$ from aqueous solutions by a new photochemical technique," Journal of Crystal Growth, vol. 198-199, pp. 308312, 1999.

[28] S. Soundeswaran, O. S. Kumar, and R. Dhanasekaran, "Effect of ammonium sulphate on chemical bath deposition of CdS thin films," Materials Letters, vol. 58, no. 19, pp. 2381-2385, 2004.

[29] O. S. Oluwafemi, N. Revaprasadu, and O. O. Adeyemi, "A new synthesis of hexadecylamine-capped Mn-doped wurtzite CdSe nanoparticles," Materials Letters, vol. 64, no. 13, pp. 15131516, 2010.

[30] V. G. Bessergenev, V. I. Belyi, A. A. Rastorguev et al., "Electroluminescent ZnS:Mn films prepared at $220-450^{\circ} \mathrm{C}$ using complex compounds with sulphur-containing ligands," Thin Solid Films, vol. 279, no. 1-2, pp. 135-139, 1996.

[31] V. Singh, V. Natarajan, and J. J. Zhu, "Luminescence and EPR investigations of Mn activated calcium aluminate prepared via combustion method," Optical Materials, vol. 30, no. 3, pp. 468-472, 2007. 

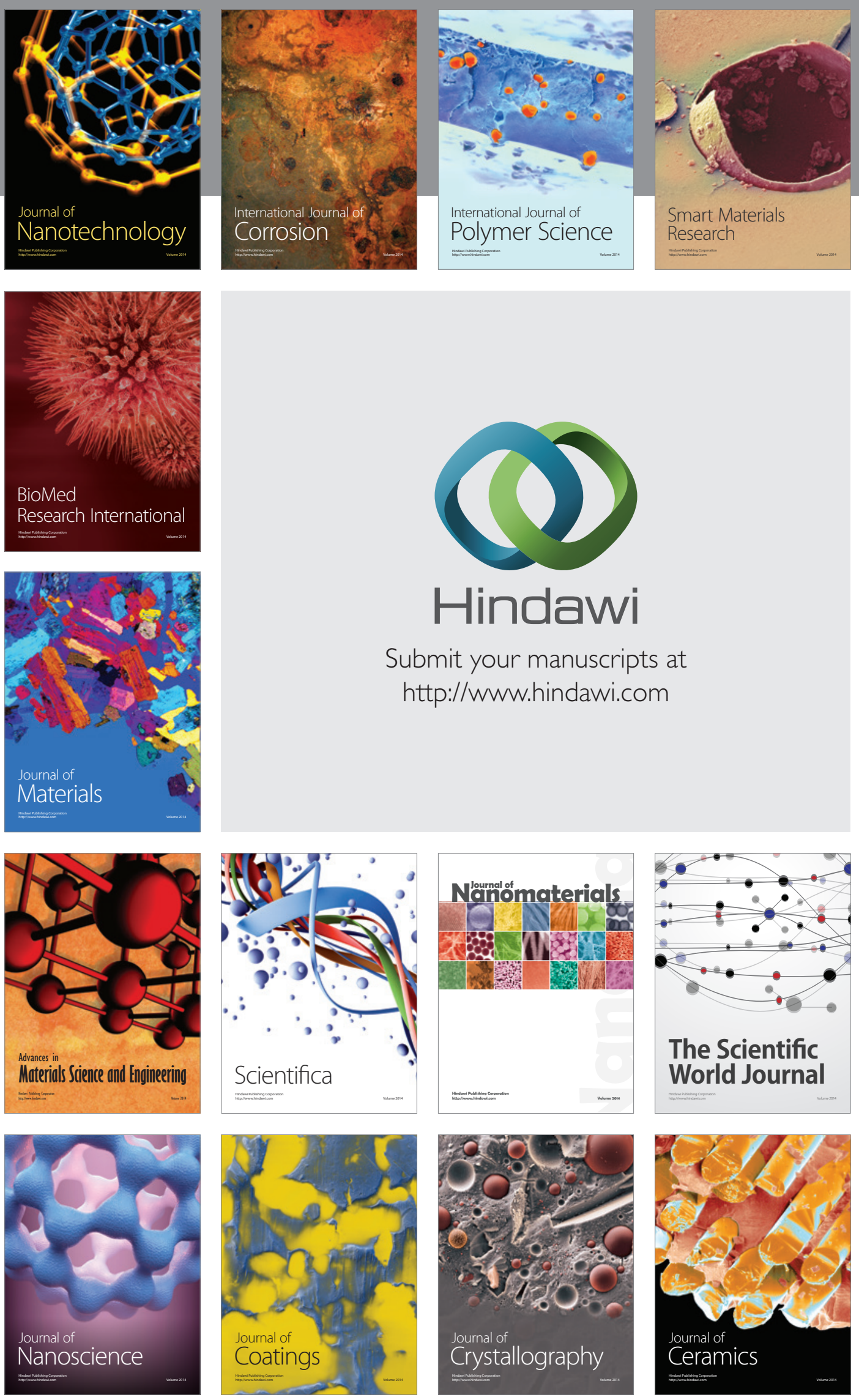

The Scientific World Journal

Submit your manuscripts at

http://www.hindawi.com

\section{World Journal}

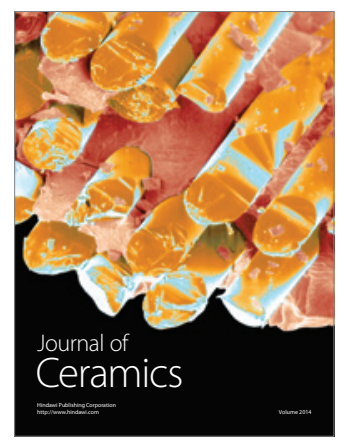

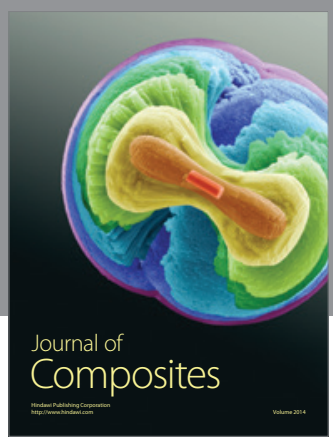
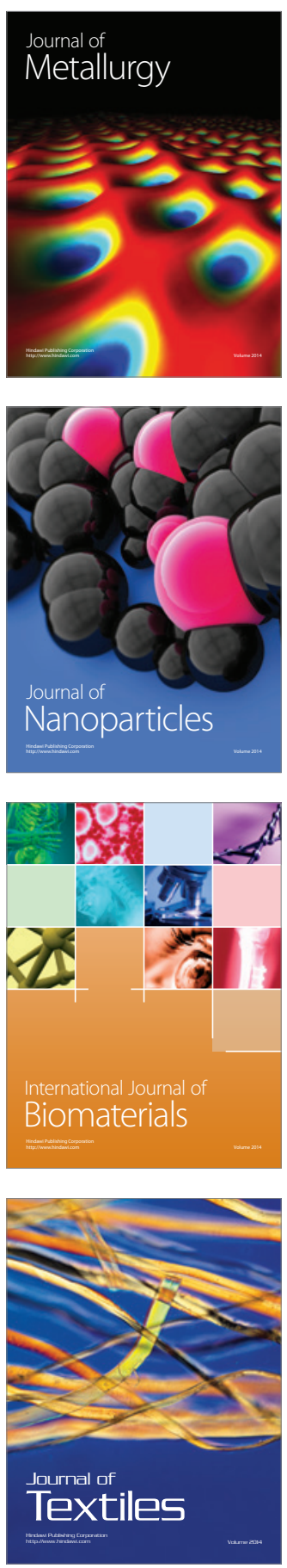